\title{
Feeding adaptations of filter feeders: Daphnia
}

\author{
T. Kmeť ${ }^{\mathrm{a}, *}$, M. Straškraba ${ }^{\mathrm{b}, 1}$ \\ a Department of Computer Science, Faculty of Natural Sciences, Constantine the Philosopher University, \\ Tr. A. Hlinku 1, 94974 Nitra, Slovak Republic \\ ${ }^{\mathrm{b}}$ Biomathematical Laboratory, Academy of Sciences of the Czech Republic and Faculty of Biological Sciences, \\ South Bohemian University, Branišovská 3137005 České Budějovice, Czech Republic
}

Received 23 September 2002; received in revised form 3 February 2004; accepted 12 March 2004

\begin{abstract}
In spite of the ongoing discussion about the functioning of filtratory apparatus of the filter feeding freshwater pelagic organism of the genus Daphnia, experiments suggest food size selectivity as well as a high degree of adaptability of filtration to food organism size. A model of feeding adaptation of a filter feeder in the framework of a pelagic ecosystem is constructed by modifying the simplified ecosystem model AQUAMOD for the presence of several species of algae of different size.

The assumption that filtration adaptability is an optimization type process is incorporated. Two possible strategies were followed: an instantaneous optimality at each time interval and an integral formulation, maximization of the integral biomass over 1-year time period. Numerical simulations as well as theoretical calculations were performed with the model. The results suggest, that the feedback between food selection by Daphnia and algal size composition is very strong.

When growth rates of several species of algae of different size is limited by a single nutrient and a value of Daphnia filter density is constant, competitive exclusion principle may hold, only one species survives.

Simulations for different constant values of Daphnia filter density show an effect not only on the size of algae surviving, but also on the number of species able to survive. The integral formulation results in higher biomass suggesting that the organisms do better if not reacting only on immediate changes but having developed mechanisms consistent with more long-term considerations. (c) 2004 Elsevier B.V. All rights reserved.
\end{abstract}

Keywords: Feeding adaptation; Daphnia; AQUAMOD mathematical models; Optimal control problem

\section{Introduction}

In this paper, we consider a simplified ecosystem model AQUAMOD for the presence of several species of algae of different size. The model consists of phosporus $\left(x_{1}\right)$ as a limiting nutrient for growth of four species of algae of different size $\left(x_{2}-x_{5}\right)$ and zooplankton $\left(x_{6}\right)$. Similar models of $n$ species of microorganisms competing exploitatively for a one, two

\footnotetext{
* Corresponding author.

E-mail address: tkmet@ukf.sk (T. Kmě́).

${ }^{1}$ Author died before this paper was completed.
}

or more growth-limiting nutrients are used to study continuous culture of microorganisms in chemostat under constant condition (Wolkowicz and Xia, 1997; Wolkowicz et al., 1997; Li et al., 2000; Li and Smith, 2001) without of any predators. All coefficients describing maximum uptake rate, mortality rate, etc. occuring in these models are supposed to be constant.

Description of chemostat in detail and general theory of chemostat is given by Smith and Waltman (1995).

Adaptability and in general control over own activity belong to basic features specific for biological objects, responsible for their fitness to the environment. 
Table 1

Equations of the model in the ecological formulation (and the corresponding mathematical notation used in Table 2.)

\begin{tabular}{cll}
\hline Size-specific parameters of algae: & \\
$C_{i}$ & $\operatorname{Frz}\left(V_{i}\right)=\mathrm{FRZ} \times E_{i}(u)$ & Forcing function \\
& $E_{i}(u)=\exp \left(-0.1\left(u-u_{i}\right)^{2}\right)$ & Selectivity \\
& $V_{i}$ & Algal cell volume $\left[\mu \mathrm{m}^{3}\right]$ \\
& $u_{i}=2 \sqrt[1 / 3]{3 V_{i} / 4 \pi}$ & Diameter corresponding to $V_{i}$ \\
$p_{i}$ & $P_{\max }\left(V_{i}\right)=0.5-0.05 \mathrm{LOG}\left(V_{i}\right)$ & Species growth rate $\left[\mathrm{day}{ }^{-1}\right]$ \\
$r_{i}$ & $\operatorname{Resp}\left(V_{i}\right)=0.02+0.002 \mathrm{LOG}\left(V_{i}\right)$ & Species resp. rate of algae $\left[\mathrm{day}^{-1}\right]$ \\
$s_{i}$ & $\mathrm{KS}\left(V_{i}\right)=-5+10 \mathrm{LOG}\left(V_{i}\right)$ & Half saturation constant for $\mathrm{P}\left[\mathrm{mg} \mathrm{m}^{-3} \mathrm{P}\right]$ \\
$f_{1}$ & $\mathrm{Faz}=0.8+0.25 \cos (t)+0.12 \cos (2 t)$ & Sedimentation function \\
$f_{2}$ & $\mathrm{Temp}=12+10 \sin (t+220)$ & Water temperature $\left[{ }^{\circ} \mathrm{C}\right]$ \\
$f_{3}$ & $I_{0}=280+210 \sin (t+240)$ & Light intensity $\left[\mathrm{cal} \mathrm{cm}^{-2} \mathrm{day}^{-1}\right]$
\end{tabular}

State variables

Phosphorus $\left[\mathrm{mg} \mathrm{m}^{-3} \mathrm{P}\right]$

$$
\begin{aligned}
& \frac{\mathrm{d} P}{\mathrm{~d} t}=\operatorname{INOUT}+\sum_{i=2}^{5} \operatorname{UVOLA}(i)+\operatorname{EXCR}(i)-\operatorname{GROWTA}(i) \\
& \mathrm{INOUT}=\frac{Q}{V}(\operatorname{PRFOS}-P) \\
& \mathrm{UVOLA}(i)=\operatorname{Frz}\left(V_{i}\right) \times A(i) \times Z \times\left(1-\frac{\mathrm{APZ} \times \mathrm{KSA}}{\mathrm{KSA}+A(i)}\right) \\
& \operatorname{EXCR}(i)=\operatorname{Resp}\left(V_{i}\right) \times \operatorname{Temp} \times A(i) \\
& \operatorname{GROWTA}(i)=P_{\max }\left(V_{i}\right) \times f(\mathrm{Temp}) \times g\left(I_{0}\right) \times A(i) \times \frac{P}{P+\operatorname{KS}\left(V_{i}\right)} \\
& f(\operatorname{Temp})=\exp (0.09 \times \operatorname{Temp}), g\left(I_{0}\right)=\frac{I_{0}}{I_{0}+\mathrm{IKM}} \\
& \operatorname{ALGAE} i=1, \ldots, 4\left[\mathrm{mg} \mathrm{m}^{-3} \mathrm{CHA}\right] \\
& \frac{A(i)}{\mathrm{d} t}=\operatorname{GROWTA}(i)-\operatorname{VYZ}(i)-\operatorname{SED}(i)-\operatorname{RESP}(i)+\operatorname{INOUT}(i) \\
& \operatorname{VYZ}(i)=\operatorname{Frz}\left(V_{i}\right) \times A(i) \times Z, \quad \operatorname{SED}(i)=\mathrm{UA} \times \operatorname{Faz} \times A(i), \quad \operatorname{RESP}(i)=\operatorname{EXCR}(i) \\
& \operatorname{INOUT}(i)=\frac{Q}{V} \operatorname{PRA}(i)
\end{aligned}
$$

\begin{tabular}{|c|c|c|c|}
\hline$a_{1}$ & UA & 0.05 & Sedimentation rate $\left[\mathrm{day}^{-1}\right]$ \\
\hline$a_{2}$ & $A P Z$ & 0.6 & $\begin{array}{l}\text { Maximum efficiency of } \\
\text { zooplankton assimilation }\end{array}$ \\
\hline$a_{3}$ & $C P$ & 0.05 & $\begin{array}{l}\text { Recalculation from units of } \\
\text { algae to units of zooplankton }\end{array}$ \\
\hline$a_{4}$ & $K S A$ & 60 & $\begin{array}{l}\text { Half saturation constant for } \\
\text { zooplankton feeding }\left[\mathrm{mg} \mathrm{m}^{-3} \mathrm{CHA}\right]\end{array}$ \\
\hline$a_{5}$ & MORTZ & 0.03 & Zooplankton mortality $\left[\mathrm{day}^{-1}\right]$ \\
\hline$a_{6}$ & $\mathrm{ZO}$ & 0.002 & $\begin{array}{l}\text { Inflow of zooplankton } \\
{\left[\mathrm{m}^{-3} \mathrm{Cday}^{-1}\right]}\end{array}$ \\
\hline$a_{7}$ & $Q / V$ & 0.1 & Hydraulic loading $\left[\right.$ day $\left.^{-1}\right]$ \\
\hline$a_{8}$ & PRFOS & 200 & $\begin{array}{l}\text { Inflow phosphorus } \\
\text { concentration }\left[\mathrm{mg} \mathrm{m}^{-3} \mathrm{P}\right]\end{array}$ \\
\hline$a_{9}$ & FRZ & 0.9 & $\begin{array}{l}\text { Zooplankton filtration rate } \\
{\left[\mathrm{m}^{-3} \mathrm{Cday}^{-1}\right]}\end{array}$ \\
\hline$a_{10}$ & IKM & 120 & $\begin{array}{l}\text { Half saturation constant for } \\
\text { light }\left[\mathrm{cal} \mathrm{cm}^{-2} . \text { day }^{-1}\right]\end{array}$ \\
\hline$a_{11}-a_{14}$ & $\operatorname{PRA}(i)$ & 0. & $\begin{array}{l}\text { Inflow of phytoplankton } \\
\text { concentration }\left[\mathrm{mg} \mathrm{m}^{-3} \mathrm{CHA}\right]\end{array}$ \\
\hline
\end{tabular}

Zooplankton $\left[\mathrm{mg} \mathrm{m}^{-3} \mathrm{P}\right]$

$$
\begin{aligned}
& \frac{\mathrm{d} Z}{\mathrm{~d} t}=\mathrm{GRWTZ}-\mathrm{MORTAL}+\mathrm{ZO} \\
& \mathrm{GRWTZ}=\sum_{i=1}^{4} \operatorname{Frz}\left(V_{i}\right) * A(i) * Z * \frac{\mathrm{APZ} * \mathrm{KSA} * \mathrm{CP}}{\mathrm{KSA}+A(i)} \\
& \mathrm{MORTAL}=\operatorname{MORTZ} \times Z
\end{aligned}
$$

Parameters 
In ecology it did not receive until now much attention, both empirically and theoretically.

The present concept of fitness is autecological, directed to life history of individual species (Stearns, 1977). The tight coupling of the organism and the environment and among different organisms is neglected. Our hypothesis is that feedback relations between the given species, its preys and predators as well as its abiotic environment result in organism behaviour different from the one predicted without respect to the adaptation. The present study is a search for methodology to evaluate the components of fitness in the ecosystem context. Rather than using an abstract approach, we have included the adaptability of an organism into a functioning, simple ecosystem model to test our hypothesis.

In the absence of a general theory, it seems useful to study first some specific examples of adaptation for which empirical ideas exist. Cladocera with their important position in the aquatic pelagial of the temperate region (Peters and De Bernardi, 1987) represents such a well studied example of selfcontrol, particularly as concerns their feeding abilities (Scheffer, 1999; Lampert and Brendelberg, 1996; Pop, 1991; Machacek, 1998). When cladocerans are subject to different food concentrations, they switch, at a concentration called incipient limitation level, from the maximum filtration rate, to a very exact adjustment of the rate just to keep the amount of food obtained constant (e.g. Kasprzak et al., 1986, summary in Lampert, 1987). In spite of a relatively simple morphology, they are able to select suitable and unsuitable food (e.g. Meise et al., 1985), and also to change their filtration rates on a daily basis in accordance with food availability (Haney, 1985).

The feature we are interested here is the ability of Cladocera to adapt both the filtration area and filter density to the amount and size structure of the food particles (algae) population (Koza and Kořínek, 1985; Kořínek et al., 1986; Mangalo, 1987). The assumption that filtration in aquatic filter feeders is an optimal process was followed by Lehman (1976). One of his postulates is that feeding activity ceases at very low food concentrations. Porter et al. (1983) claim that their observations do not support this postulate. However, their earlier data (Porter et al., 1982) indicate a threshold value for feeding at a concentration of about $5 \times 10^{2} \mathrm{~mm}^{-3}$ algal cells and also a decreased grazing (ingestion) rate at the lowest food concentration of
Table 2

System of equation of the model in the mathematical notation

$$
\begin{aligned}
\frac{\mathrm{d} x_{1}}{\mathrm{~d} t}= & a_{7}\left(a_{8}-x_{1}\right) \\
& -\sum_{i=2}^{5}\left(\frac{d_{1} x_{i} p_{i} x_{1}}{x_{1}+s_{i}}+r_{i} f_{2} x_{i}+x_{i} x_{6} C_{i}\left(1-\frac{d_{4}}{a_{4}+x_{i}}\right)\right) \\
\frac{\mathrm{d} x_{i}}{\mathrm{~d} t}= & \frac{d_{1} x_{i} p_{i} x_{1}}{x_{1}+s_{i}}-r_{i} f_{2} x_{i}-x_{i} x_{6} E_{i}-d_{2} x_{i}+a_{i+9} a_{7}, \\
& \text { for } i=2, \ldots, 5 \\
\frac{\mathrm{d} x_{6}}{\mathrm{~d} t}= & x_{6}\left(d_{3} \sum_{i=2}^{5} \frac{C_{i} x_{i}}{a_{4}+x_{i}}-a_{5}\right)+a_{6} \\
\text { where } & C_{i}=E_{i}(u) a_{9}, d_{1}=f(\text { Temp }) g\left(I_{0}\right), d_{4}=a_{2} a_{4}, \\
& d_{3}=a_{3} d_{4}, d_{2}=a_{1} f_{1}
\end{aligned}
$$

their experiment. In all experiments performed up to now, a region over which the amount of food gathered remains constant is always detected (Lampert, 1987).

Most of the above ideas are based on the assumption, that filter feeding is a simple screening process, the efficiency of filtration being dependent on the relation between filter density and the size of food particles. Details of the particle capture process by Daphnia and other filter feeders are a subject of hearty debate, with one school stressing inadequacies of the "classical" view of simple filtration (Porter et al. 1983b; Ganf and Shiel, 1985), the other accumulating arguments for its validity (Brendelberger, 1985; Brendelberger et al., 1986; Fryer, 1987). Gerritsen et al. (1988) used epifluorescent microscopic video image analyses and high-speed microcinematography to show new details of Daphnia suspension feeding, suggesting that simple sieving according to the classical views is an unlikely process for routine particle collection.

Our assumption is that the process of food selection, like any other life history process, is organised as to increase the organism fitness. The connection between feeding and fitness was demonstrated for Daphnia magna in a careful experimental study by Porter et al. (1982). Fitness is difficult to be measured directly, particularly in the ecosystem context. We are using an

Table 3

Parameters for the four "species" of algae

\begin{tabular}{lcccc}
\hline$V_{i}$ & 50 & 500 & 2500 & 5000 \\
$u_{i}$ & 4.572 & 9.849 & 16.84 & 21.22 \\
$P_{\max }\left(V_{i}\right)$ & 0.4151 & 0.3651 & 0.3301 & 0.3151 \\
$\operatorname{KS}\left(V_{i}\right)$ & 11.99 & 21.99 & 28.98 & 31.99 \\
$\operatorname{Resp}\left(V_{i}\right)$ & 0.0234 & 0.0254 & 0.0268 & 0.0274 \\
\hline
\end{tabular}


indirect measure, which we consider consistent with the conclusions of Porter et al. (1983): "Daphnia are adapted for rapid population increase and for recovery from mass mortality in cyclical environments with conditions for optimal growth that can be expected to reoccur but are of highly variable duration". This strategy is reflected in the trend to obtain maximum instantaneous biomass possible within the limits of the environmental constraints and the organism adaptability. Simultaneously, we evaluate another possible strategy, to adapt in a way conforming to more long-term goals: the population should reach in a variable environment the highest possible integral of biomass over time. Our selected time unit is 1 year, based on the cyclicity of conditions in temperate region.

In the absence of detailed understanding of the food selection process by Daphnia, simplified assumptions are made, based on accepted generalizations of empirical observations. The size of food particles seems to be an important variable of food selection (for feed- ing experiments see Lampert, 1987, in the ecosystem context e.g. Bergquist et al., 1985; Lehman and Sandgren, 1985, theoretical investigation by Carpenter and Kitchell, 1984). We are using a modification of our earlier model covering the generalized size dependence of the ecophysiological parameters of algae.

Under the situation specified above, the goal of the present paper is to follow how far does the incorporation of the optimality notion for zooplankton feeding adaptation into an ecosystem model result in trends of changes, similar to those observed in nature. Therefore, it is a methodical question rather than an attempt to realistically simulate specific situations. Only the adaptation of zooplankton filtration to the species composition of phytoplankton is modelled, the adaptation to phytoplankton concentration being neglected.

This paper is organized as follows. In the next section, we present a description of a model and selectivity function of zooplankton $E_{i}$. Section 3 deals with global behaviour of the model. In Section 4, we give

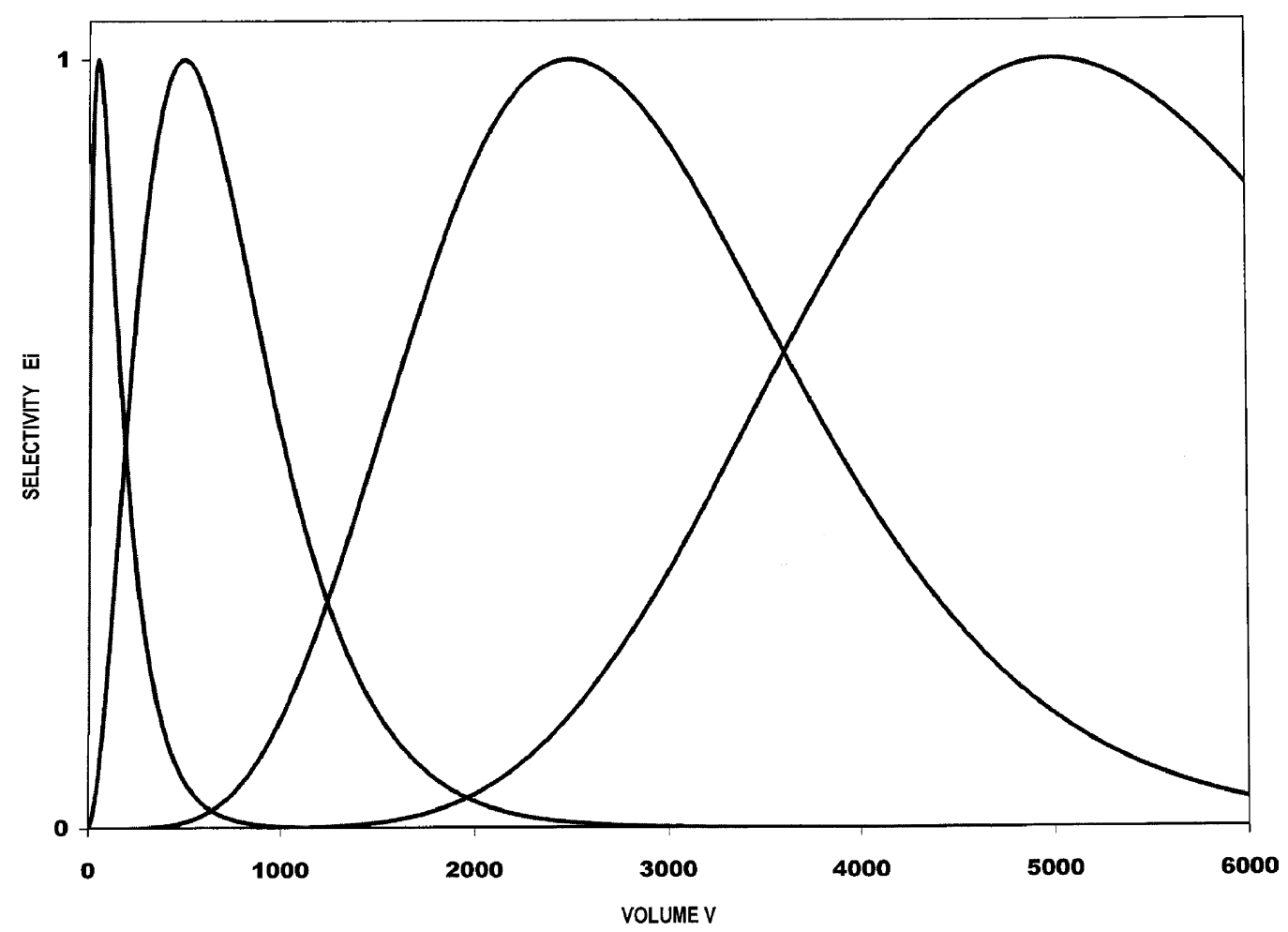

Fig. 1. Assumed size selectivity of algae for different values of $V_{i}$. Each curve represents the selectivity of Daphnia with a particular density of setae. For each $V$, the peak of the curve corresponds to a given value of $V_{i}$. 
numerical analysis of the model for different filter density $u$ under constant environmental condition.

\section{Model description}

The model used is given in Tables 1 and 2 in ecological and mathematical notation, respectively. It is derived from the models of the series AQUAMOD (e.g. Straškraba and Gnauck, 1985; Kmeť and Straškraba, 1989) modified by the inclusion of several "species" of algae. The description of the light dependence of algae is highly simplified. Instead of an approximative integration of the algal growth over depth and time distribution of light intensity only a simple function $g(I)$ is used, describing a Michaelis-Menten type dependence with the halfsaturation constant for light IKM. We consider this oversimplification appropriate for the purposes of this paper.

Four species of algae were considered during the computations performed: $x_{2}, \ldots, x_{5}$. Each "species" is represented by a particular algal cell (or colony) volume. The volumes were set arbitrarily to $\left(V_{i}=\right.$ $50,500,2500$ and $\left.5000 \mu \mathrm{m}^{3}\right)$, to approximate the set of "edible" algal sizes commonly occurring in our reservoirs. The ecological parameters of the algae are considered functions of $V_{i}$ in agreement with Radtke and Straškraba (1982) (model SELFOPT in Straškraba and Gnauck, 1985). Table 3 gives the corresponding values used in the present simulations. However, for other values of $V_{i}$ it is possible to derive the parameters from the functions $P_{\max }\left(V_{i}\right), \operatorname{KS}\left(V_{i}\right)$ and $\operatorname{Resp}\left(V_{i}\right)$ given in Table 1. It is to be noted that $P_{\max }$ corresponds to light saturation and temperature of $0{ }^{\circ} \mathrm{C}$; for $20^{\circ} \mathrm{C}$, the growth rate will be about 7.2 times higher. The high values of PRFOS are used to simulate eutrophic conditions. For the filtration capability of zooplankton, we assume that algal volumes selected at a given setting of the filtratory apparatus have log-normal distribution. This is identical with the "size limited predators" of Zaret (1980) and the function we propose is approximately identical with the "selectivity" by this class of
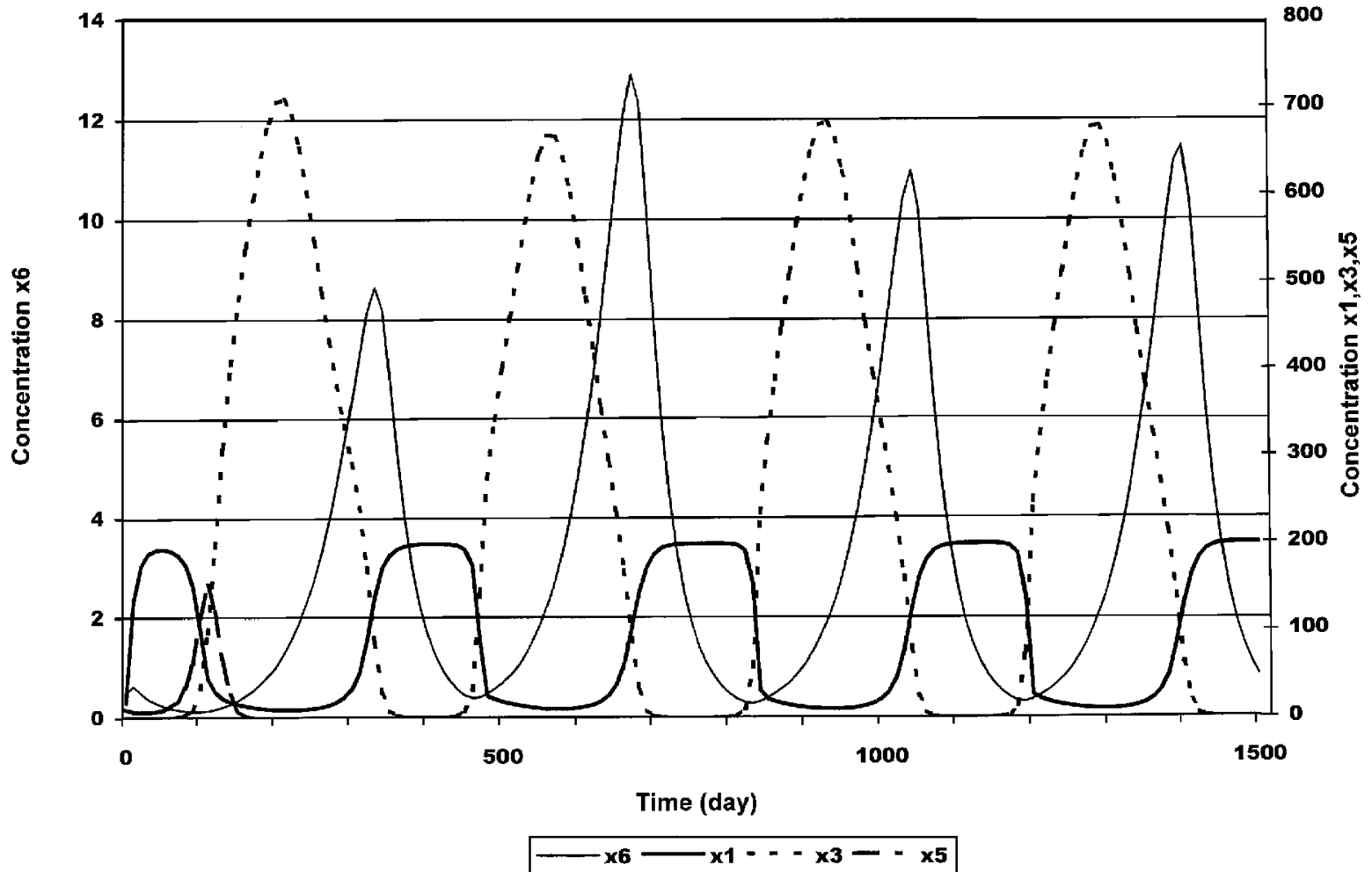

Fig. 2. Two years of simulation of the four sizes of algae with $u=$ constant $=4$. The initial conditions were set as follows: $x_{1}^{\circ}=17.3, x_{2}^{\circ}=10.1, x_{3}^{\circ}=0.1, x_{4}^{\circ}=0.01, x_{5}^{\circ}=10, x_{6}^{\circ}=0.5$ under periodically varying environmental conditions. 
predators as given by Zaret (1980). The description of selectivity $E_{i}$ is as follows:

$E_{i}(u)=\exp \left(-0.1\left(u-u_{i}\right)^{2}\right)$

where $u$ is the value of setal density directly related to the algal diameter for which selectivity is maximal and $u_{i}=2 \sqrt[1 / 3]{3 V_{i} / 4 \pi}$ is the diameter corresponding to each algal cell volume $V_{i}$.

Because of the nonlinear relationship between diameters and algal cell volume $\left(V_{i}=4 / 3 \pi\left(u_{i} / 2\right)^{3}\right)$, the normal distribution given by Eq. (1) converts to a shape of a log-normal character (Fig. 1). The specific filtration rate of algae of different sizes (volumes) of the population adapted to certain condition (i.e., with certain values of $u$ becomes

$\operatorname{Frz}\left(V_{i}\right)=\mathrm{FRZ} \times E_{i}(u)$

where FRZ is the filtration rate for algae of the optimal size, i.e., those which are filtered with the selectivity factors $E_{i}\left(u_{i}\right)=1$.

\section{Examination of the global model behavior}

Assume in this paragraph that $E_{i}(u)=$ constant for $i=2, \ldots, 5$. Assume also $a_{j}>0$ for $j=5, \ldots, 14$. We will show that under these assumptions our system under the effect of periodically varying environmental conditions has a periodic solution with the period $360^{\circ}$ ( $\sim 360$ days, $\sim 1$ years).

Let us denote

$z(t)=x_{1}(t)+\cdots+x_{6}(t)$.

Denote further

$b=\min \left(a_{7}, d_{2}, a_{5}\right), \quad a=a_{7}\left(a_{6}+a_{11}+\cdots+a_{14}\right)$.

It follows that

$\stackrel{\circ}{z}(t) \leq-z(t) b+a$.

By variation of constants we obtain

$z(t) \leq \exp (-b t)\left(z^{\circ}-a\right)+a$

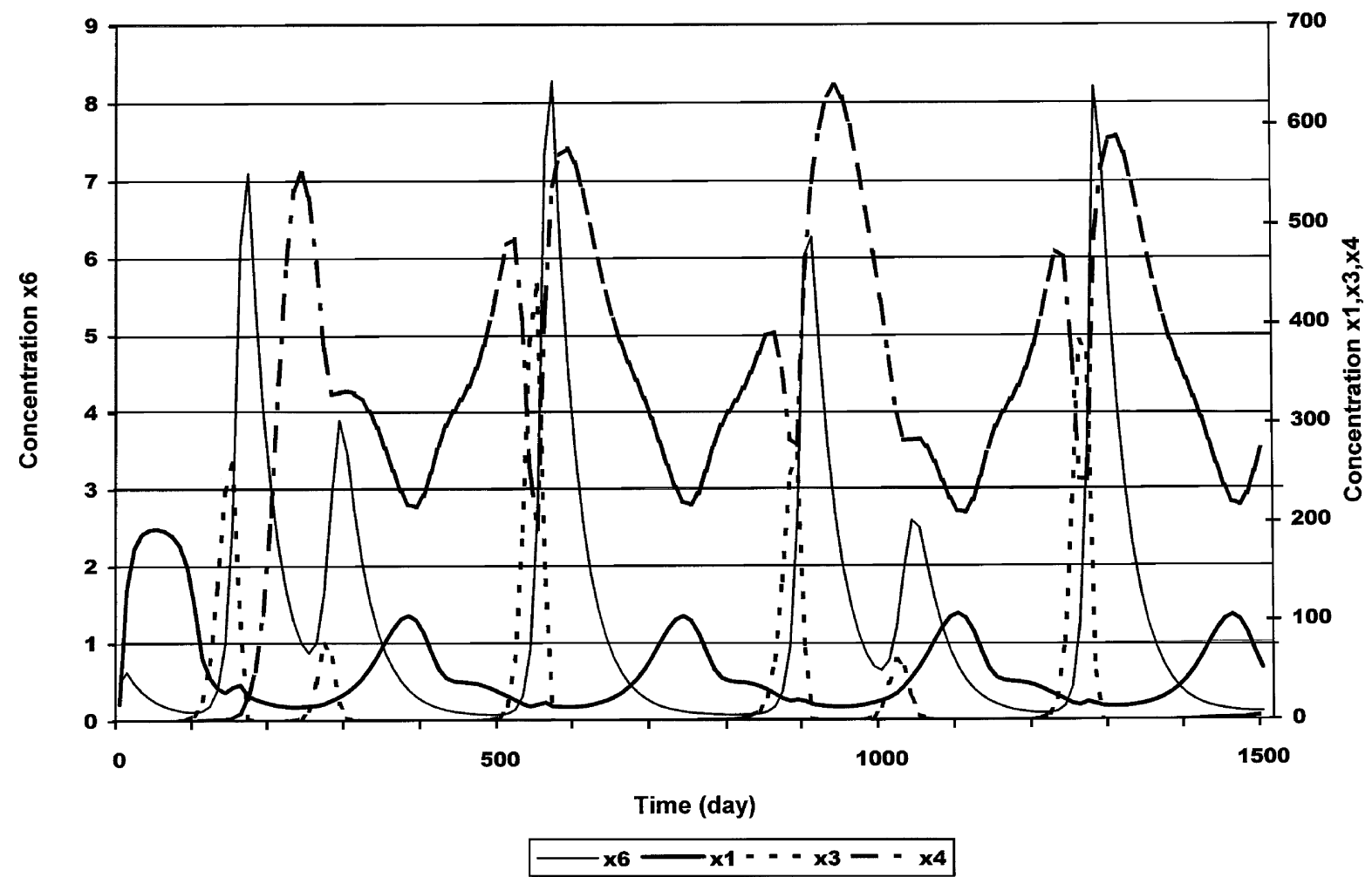

Fig. 3. The same as Fig. 2, $u=5$. 
where $z^{\circ}=x_{1}^{\circ}+\cdots+x_{6}^{\circ}$ and $x^{\circ}$ is the initial condition of the solution $x\left(t, t_{\circ}, x^{\circ}\right)$, i.e. $x\left(t=t_{\circ}, x^{\circ}\right)=x^{\circ}$.

It follows that

$\lim _{t \rightarrow \infty} z(t) \leq a$.

Now, we will demonstrate that the solutions of the system are ultimately bounded, i.e., it exists $B>0$ and $T>0$ such that for all solutions $x\left(t, t_{\circ}, x^{\circ}\right)$ of the system holds that $x\left(t, t_{\circ}, x^{\circ}\right)<B$ for all $t>t_{\circ}+T$, where $B$ does not depend on $t_{\circ}$ and $x^{\circ}$ and $T$ can depend on $t_{\circ}$ and $x^{\circ}$. Set $T=1$ for $z^{\circ} \leq a+1, T=$ $\left(\ln \left(z^{\circ}-a\right)\right) / b$ for $z^{\circ}>a+1$ and $B=3(a+1)$. Evidently holds true that $x\left(t, t_{\circ}, x^{\circ}\right)<B$ for $t>t_{\circ}+T$. The solutions of the system are therefore ultimately bounded. According to Yoshizawa (1975), there exists a periodic solution with the period 360 days (see Figs. 2 and 3 for $u=4$ and 5, respectively) and the following proposition is true.
Proposition 1. System (1) given in Table 2 under periodically varying environmental conditions with period 360 days has a periodic solution with the same period.

During constant density of setae $(u=$ constant) the zooplankton captures only phytoplankton of a certain size range dependent on $u$. The growth of other species of algae which are not at all or only to a limited extent consumed is therefore limited mainly by nutrients. We will demonstrate that the species which is not intensively consumed by zooplankton and has therefore the best conditions for development dominates in the struggle for existence over other species.

Assume further that $a_{i}=0$ for $i=11, \ldots, 14$.

Derivatives $x^{\circ}{ }_{i}$ for $i=2, \ldots, 5$ can be written in the following way

$\stackrel{\circ}{x}_{i}=x_{i} F_{i}(x, t)$,

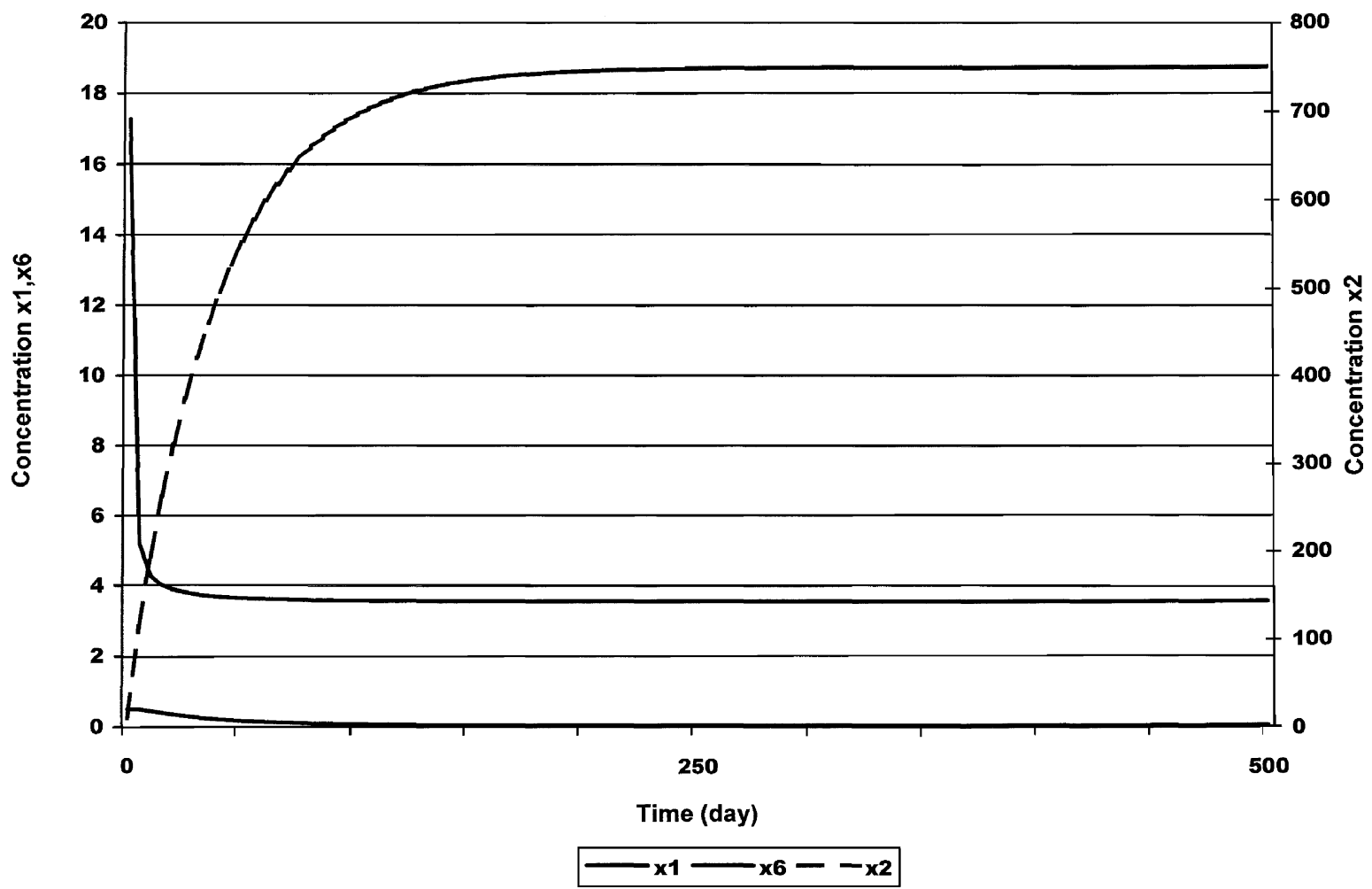

Fig. 4. Numerical solution of system (1) under constant environmental conditions for $u=17$. The initial conditions were set as follows: $x_{1}^{\circ}=17.3, x_{2}^{\circ}=10.1, x_{3}^{\circ}=0.1, x_{4}^{\circ}=0.01, x_{5}^{\circ}=10, x_{6}^{\circ}=0.5$. 
where

$F_{i}(x, t)=d_{1} p_{i} \frac{x_{1}}{x_{1}+s_{i}}-E_{i} x_{6}-d_{2}-r_{i} f_{2}$.

As follows from the shape of functions $p_{i}$ and $s_{i}$, the following holds true:

$p_{i}>p_{j}, \quad r_{i}<r_{j} \quad$ and $\quad s_{i}<s_{j}$ for $i<j$.

Therefore,

$\frac{p_{i}}{x_{1}+s_{i}}>\frac{p_{j}}{x_{1}+s_{j}}$ for $i<j$.

In respect to the shape of the function $E_{i}$ for $u$ sufficiently large $\left(u>u_{2}\right)$

$E_{2}<E_{j}$ for $j=3-5$.

Calculate the derivatives

$\left(\frac{\stackrel{\circ}{x_{i}}}{x_{j}}\right)=\frac{x_{i}}{x_{j}}\left(F_{i}(x, t)-F_{j}(x, t)\right)$.
In respect to (3) and (4), the following holds true $F_{2}(x, t)>F_{j}(x, t)$ for $j=3-5$.

By variation of constants, we obtain $\frac{x_{2}(t)}{x_{j}(t)}=\frac{x_{2}(0)}{x_{j}(0)} \exp \left(\int_{0}^{t}\left(F_{2}(x, s)-F_{j}(x, s)\right) \mathrm{d} s\right)$.

It is true that

$\lim _{t \rightarrow \infty} \frac{x_{2}(t)}{x_{j}(t)}=\infty$

Due to boundedness of the solutions, $x_{j}(t)$ converges to zero for $j=3-5$ and the following proposition is true.

Proposition 2. In respect to (3), (4) and u sufficiently large the species of algae are not able to coexist.

Remark. In a similar way, we can show that for $x_{2}=$ $0, x_{4}$ and $x_{5}$ go extinct for $t \rightarrow \infty$.

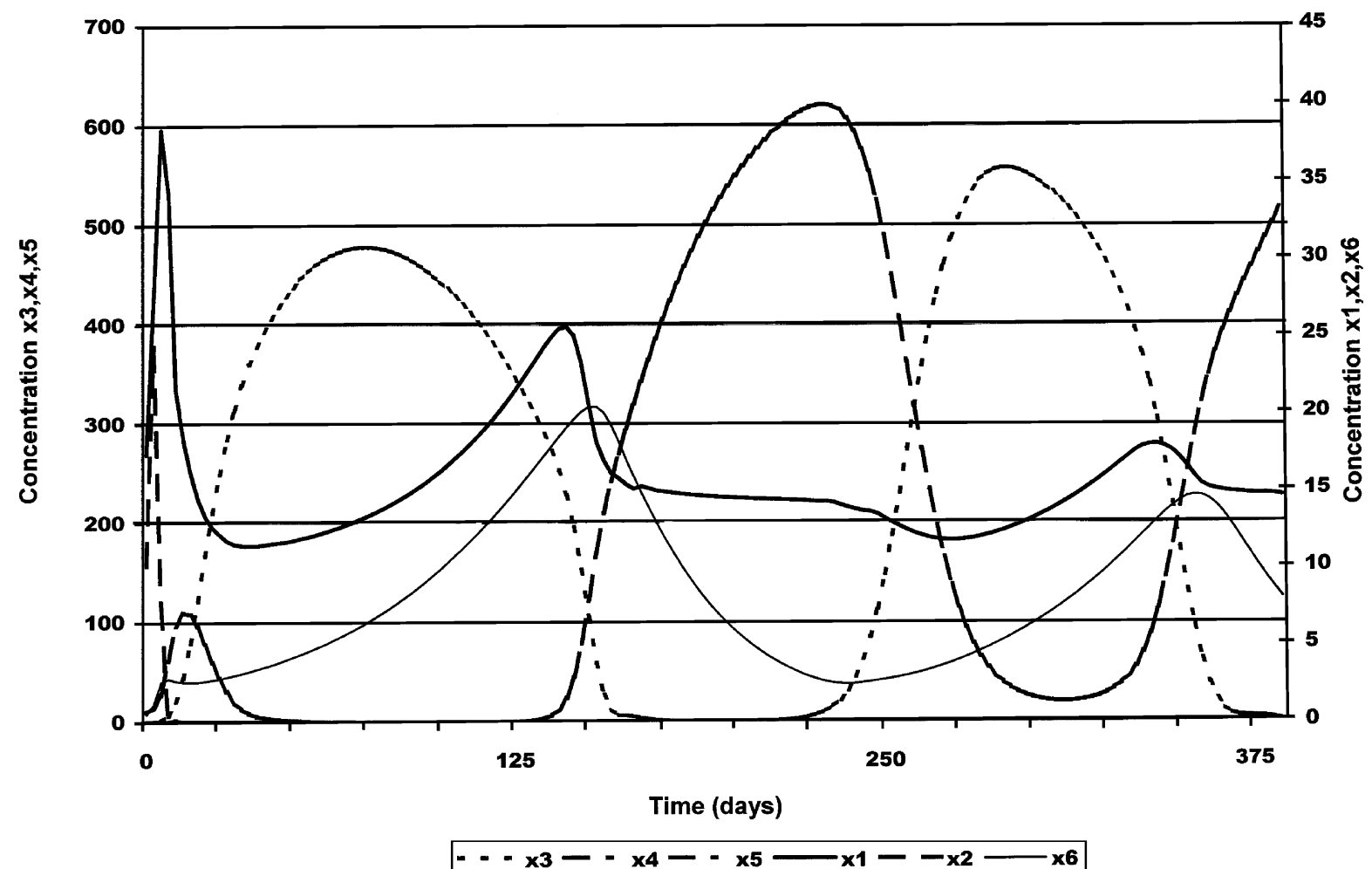

Fig. 5. Numerical solution of system (1) under constant environmental conditions for $u=4$. The initial conditions were set as follows: $x_{1}^{\circ}=17.3, x_{2}^{\circ}=10.1, x_{3}^{\circ}=0.1, x_{4}^{\circ}=0.01, x_{5}^{\circ}=10, x_{6}^{\circ}=0.5$. 


\section{Model simulation}

Figs. 4-6 show the dynamics of algae in a simplified aquatic ecosystem simulating the presence of zooplankton of different body size and correspondingly different filter density, $u$ under constant environmental condition. The comparison of the three figures for selected arbitrary constant values of $u$ demonstrates that not only the size but also the number of algal species surviving in the system depends on $u$. For the environmental conditions specified for the given simulation experiment and $u=17$ (Fig. 4) the algal sizes $x_{j}$ for $j=3,4,5$ converge to zero and only the smallest phytoplankton species $x_{2}$ survives. This is equivalent to assume that Daphnia in this experiment is an effective screener of larger food particles, the small ones remaining much less affected. When $u$ is set to 4 or 5 in Fig. 5 and 6, i. e., the filter of Daphnia present is more dense, two species of algae are able to coex- ist. With a denser filter the smaller algae are filtered out more efficiently; because of the nonlinear effects of algal size on ecological parameters a broader spectrum of species of different sizes is able to survive in the system under the environmental conditions identical with the experiments shown in Fig. 2 and 3.

For chemostat models with one growth-limiting nutrient, we get the following cases:

1. chemostat is an inadequate environment for either population to survive,

2. model exhibits competitive exclusion.

Under constant environmental conditions, the system (1) is autonomous. With respect to (3) and $u$ constant, there are no nontrivial interior equilibria. Equilibrium point can exist only for $x_{3}=x_{4}=x_{5}=0$ (or $x_{2}=x_{3}=x_{4}=0$ and so on). Detailed analysis of similar systems is given, for example, in Kmet and Straškraba (1989), Scheffer et al. (2000).

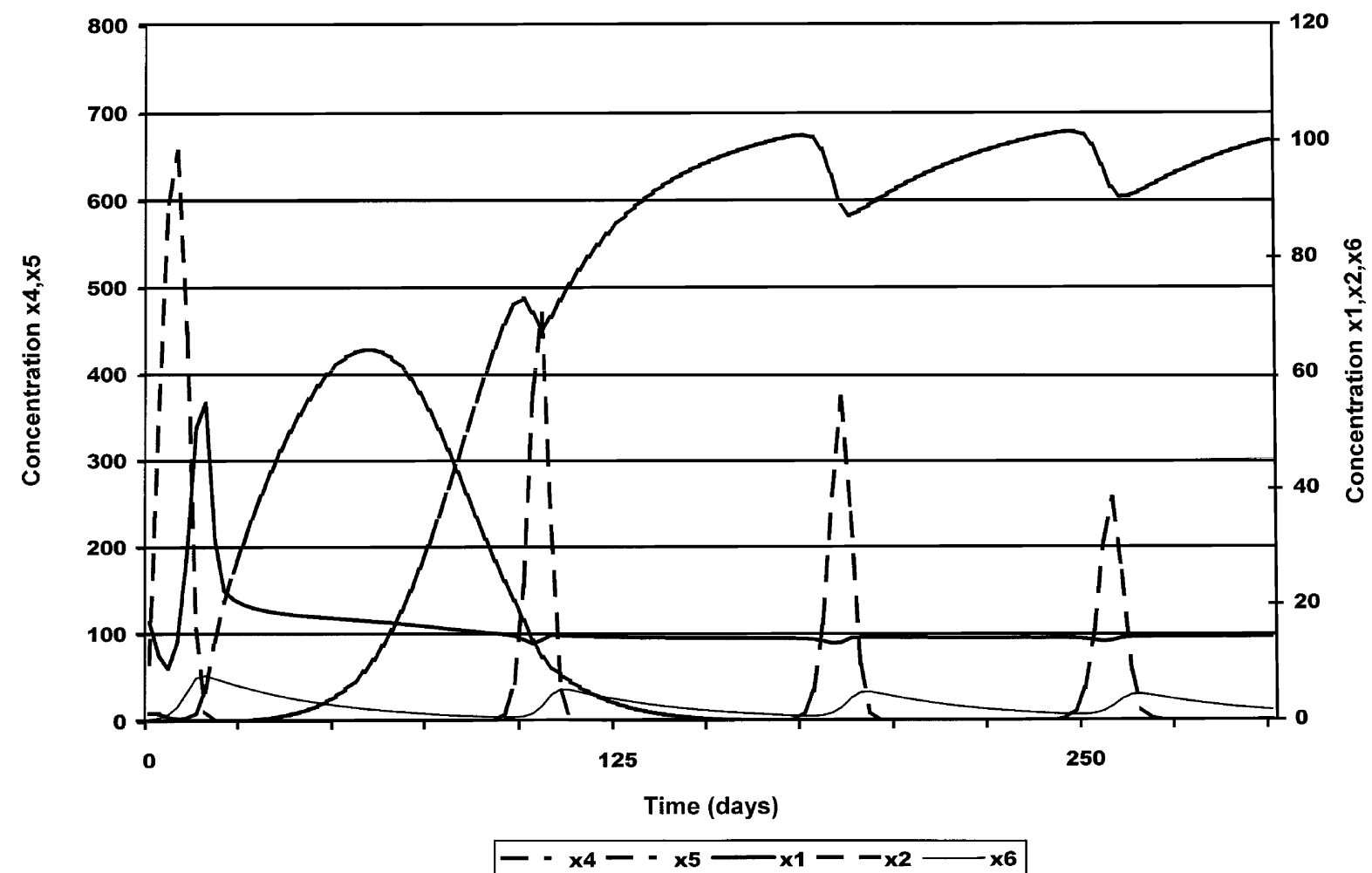

Fig. 6. Numerical solution of system (1) under constant environmental conditions for $u=5$. The initial conditions were set as follows: $x_{1}^{\circ}=17.3, x_{2}^{\circ}=10.1, x_{3}^{\circ}=0.1, x_{4}^{\circ}=0.01, x_{5}^{\circ}=10, x_{6}^{\circ}=0.5$. 


\section{Optimization}

In this section, we are interested in the ability of Cladocera to adapt both the filtration area and filter density to the amount and size structure of the food particles (algae) population. We assume that filtration in aquatic filter feeders is an optimal process of maximal feeding strategy. We will investigate two strategies (Kmeť, 1996):

(1) instantaneous maximal biomass production as a goal function (local optimality), i.e.,

${\stackrel{\circ}{x_{6}}}=f_{6}(x, u, t) \rightarrow \max$

in respect to $u$ for all $t$,

(2) integral maximal biomass (global optimality), i.e.,

$J(u)=\int_{0}^{t} x_{6}(t) \mathrm{d} t$.

\section{Local optimality.}

In the case of strategy 1 , we maximize the following function

$J(u)=\sum_{i=2}^{5} \frac{E_{i}(u) d_{3} x_{i} a_{9}}{\left(x_{i}+a_{4}\right)}$.

This function attains its maximum on the interval $\left(u_{2}, u_{5}\right)$, where $u_{2}<u_{3}<u_{4}<u_{5}$.

\section{Global optimality.}

In case of strategy 2 , we have the following optimal control problem: to find a function $u^{\wedge}(t)$, for which the goal function

$J(\hat{u})=\int_{0}^{T} x_{6}(t) \mathrm{d} t$

attains its maximum, where $T$ denotes the lifetime of an individual Daphnia.

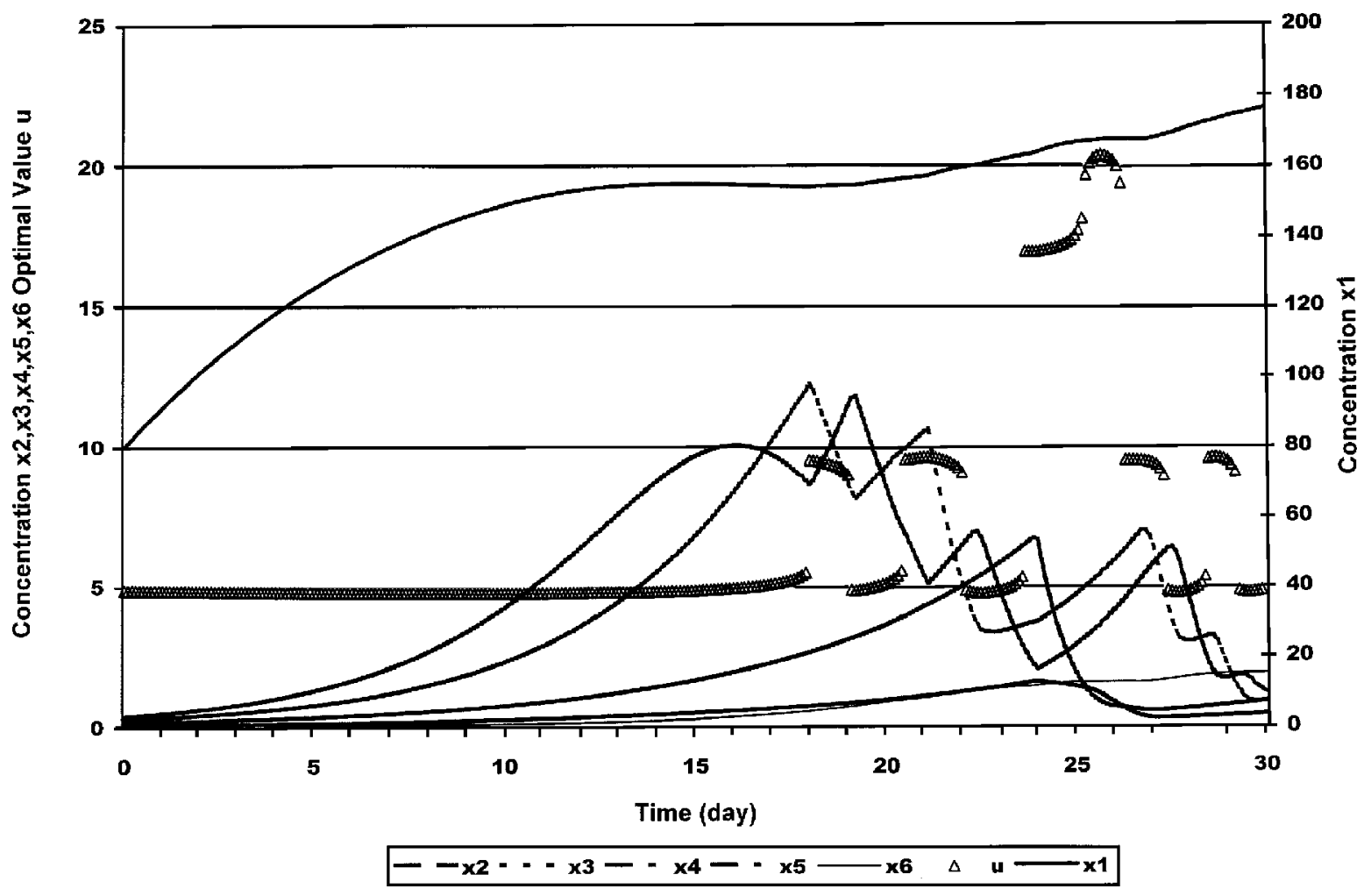

Fig. 7. Optimal solution with local strategy under constant environmental conditions. Initial conditions: $x_{1}^{\circ}=80.3, x_{2}^{\circ}=0.4, x_{3}^{\circ}=0.3$, $x_{4}^{\circ}=0.2, x_{5}^{\circ}=0.1, x_{6}^{\circ}=0.1, t=120$. 


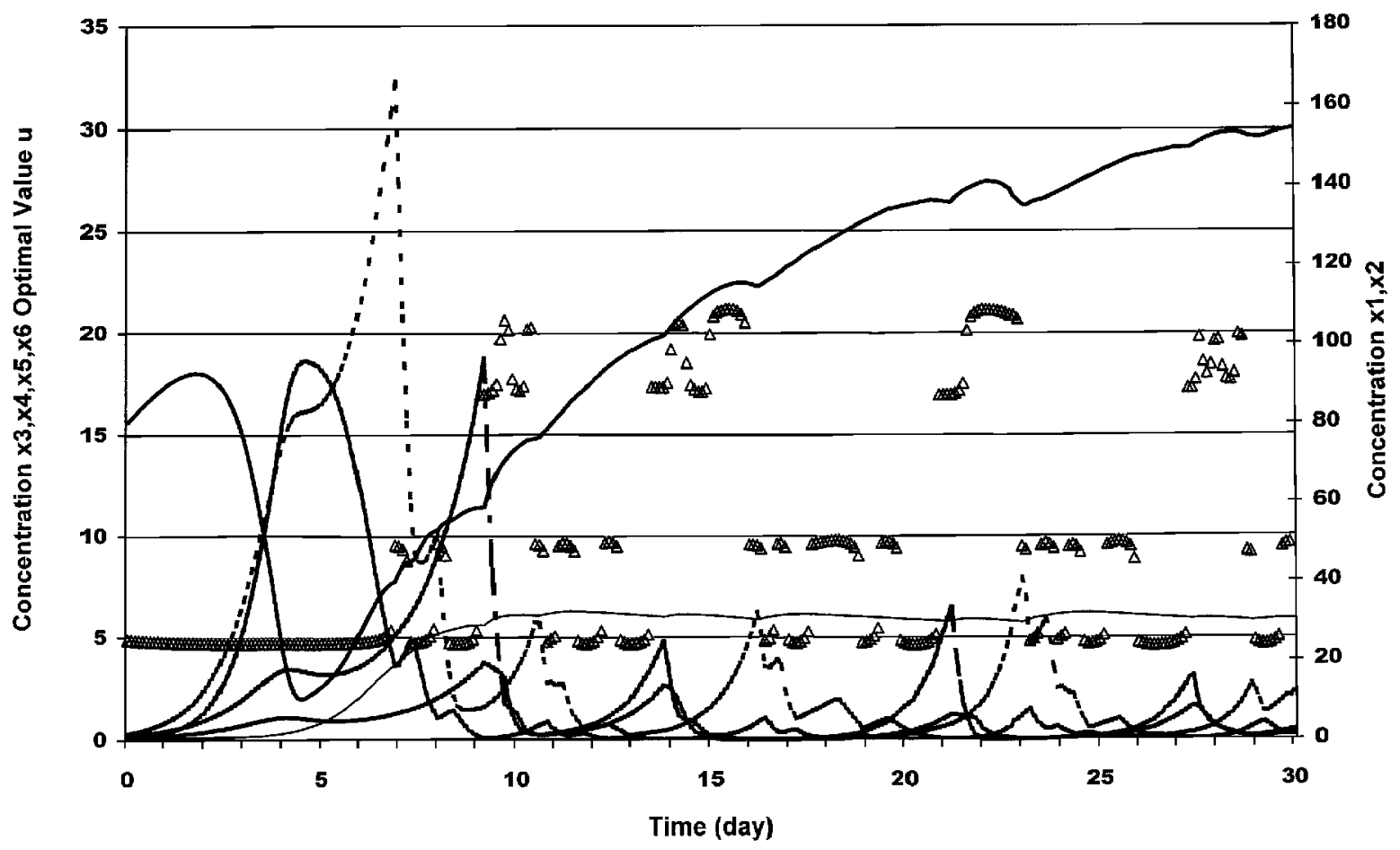

$---\times 3--\times 4-\cdots \times 5-\times 6 \quad \Delta \quad$ u $-\times 1--\times 2$

Fig. 8. Optimal solution with local strategy under constant environmental conditions. Initial conditions: $x_{1}^{\circ}=80.3, x_{2}^{\circ}=0.4, x_{3}^{\circ}=0.3$, $x_{4}^{\circ}=0.2, x_{5}^{\circ}=0.1, x_{6}^{\circ}=0.1, t=210$.

The Pontryagin maximum principle (Pontryagin et al., 1983) for this optimal control problem results for $T$ fixed and $u^{\wedge}$ optimal in the following system of equations:

$$
\begin{array}{ll}
\stackrel{\circ}{x}(t)=\frac{\partial H(x, z, u, t)}{\partial z}, & x(0)=x_{0} \\
\stackrel{\circ}{z}(t)=\frac{\partial H(x, z, u, t)}{\partial x}, & z(T)=0
\end{array}
$$

$$
H(x, z, \hat{u}, t)=\max _{u} H(x, z, u, t)
$$

where

$$
\begin{aligned}
& H(x, z, u, t) \\
& =\left(a_{7}\left(a_{8}-x_{1}\right)-\sum_{i=2}^{5}\left(\frac{d_{1} x_{i} p_{i} x_{1}}{x_{1}+s_{i}}\right.\right. \\
& \left.\left.\quad+r_{i} f_{2} x_{i}+x_{i} x_{6} C_{i}\left(1-\frac{d_{4}}{a_{4}+x_{i}}\right)\right)\right) z_{1}
\end{aligned}
$$

$$
\begin{aligned}
& +\sum_{i=2}^{5}\left(\frac{d_{1} x_{i} p_{i} x_{1}}{x_{1}+s_{i}}-r_{i} f_{2} x_{i}\right. \\
& \left.-x_{i} x_{6} E_{i}-d_{2} x_{i}+a_{i+9} a_{7}\right) z_{i} \\
& +\left(x_{6}\left(d_{3} \sum_{i=2}^{5} \frac{C_{i} x_{i}}{a_{4}+x_{i}}-a_{5}\right)+a 6\right) z_{6}+x_{6}
\end{aligned}
$$

We have solved the given optimal control problem by an iteration method described by Brunovský (1980) and by subprogram according to Pierre and Lowe (1975).

The results of numerical solutions (Figs. 7-10) have shown that the optimal strategies $u^{\sim}(t)$ and $u^{\wedge}(t)$ based on short or long-term perspective, respectively, have different time trajectory for different values of Faz $=0.8+0.25 \cos (t)+0.12 \cos (2 t)$ - sedimentation function, Temp $=12+10 \sin (t+220)$-water temperature, and $I_{0}=280+210 \sin (t+240)$-light intensity $(t=120,210)$. 


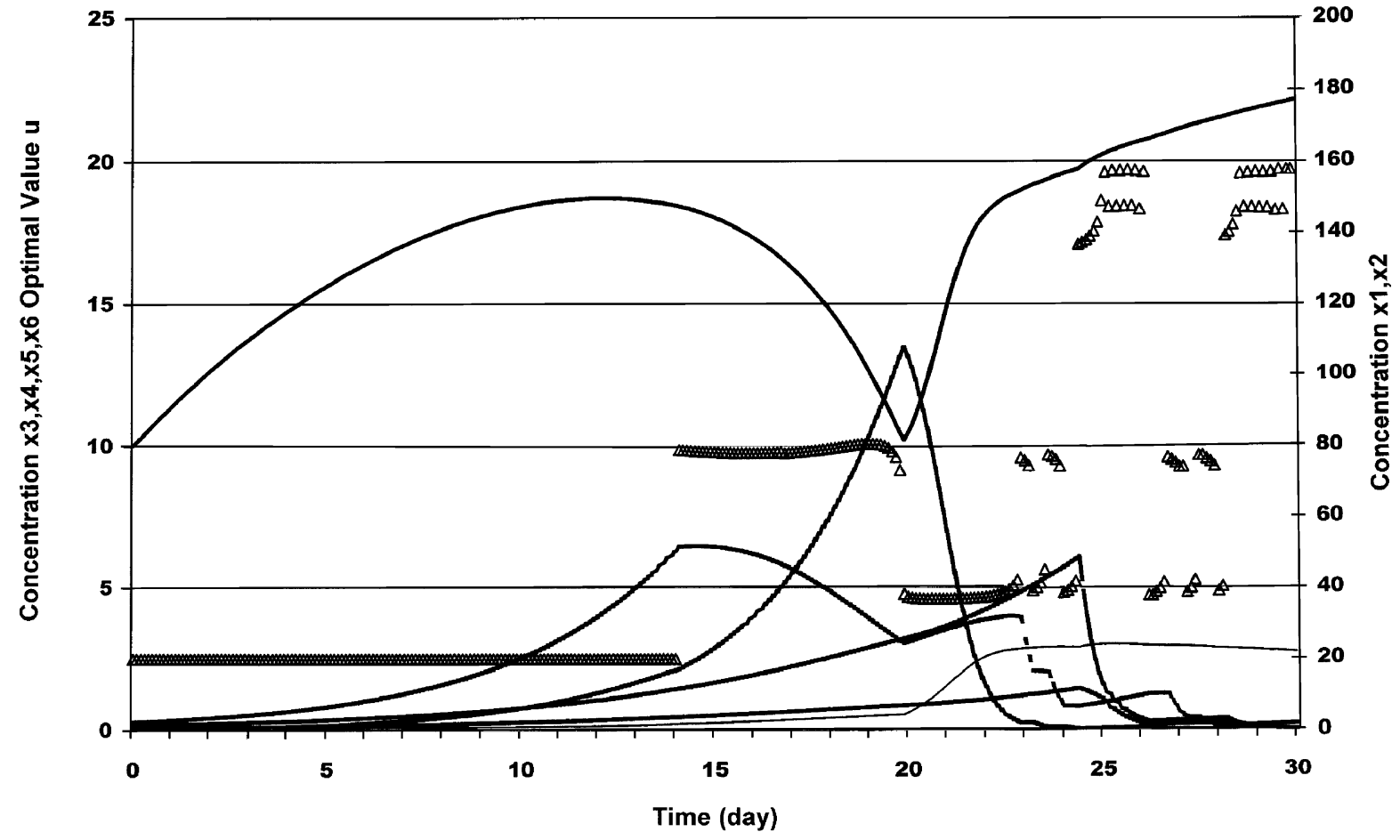

$--x 3--x 4--x 5-x 6 \quad \Delta \quad u-x 1--x 2$

Fig. 9. Optimal solution with global strategy under constant environmental conditions. Initial conditions: $x_{1}^{\circ}=80.3, x_{2}^{\circ}=0.4, x_{3}^{\circ}=0.3$, $x_{4}^{\circ}=0.2, x_{5}^{\circ}=0.1, x_{6}^{\circ}=0.1, t=120$.

When following local strategy, the selection of $u$ is that the smallest alga is filtered independently of local conditions. Switching is observed among the values of $u$ permitting maximal filtration of the individual species (Fig. 7 and 8). The initial concentrations of different algal sizes have only a minor influence. Global strategy results in a different behavior: the smallest species is not filtered at all (Fig. 9 and 10). As a result its concentration rises and only when the smallest alga reaches high concentrations, Daphnia changes the control so that this smallest species is utilized. When $u^{\wedge}(t)$ is optimal (what is valid according to numerical results) then

$J(\hat{u}(t)) \geqq J(\tilde{u}(t))$,

i.e., the total biomass for the short-term perspective is smaller or maximally equal to the biomass for the long-term perspective. The numerical results have
Table 4

Result of goal function evaluation for local and global optimality

\begin{tabular}{lll}
\hline$J\left(u^{\sim}\right)$ & 10.04 (Fig. 7) & 71.23 (Fig. 8) \\
$J\left(u^{\wedge}\right)$ & 15.2 (Fig. 9) & 80.42 (Fig. 10)
\end{tabular}

shown, that for the initial conditions considered

$J(\hat{u}(t))>J(\tilde{u}(t))$

(see Table 4).

\section{Discussion}

The results obtained confirm the hypothesis that the change of food screening process by Cladocera can be understood as an adaptation to maximize its biomass. Incorporation of this assumption into the model yields in systematic reactions of the model qualitatively con- 


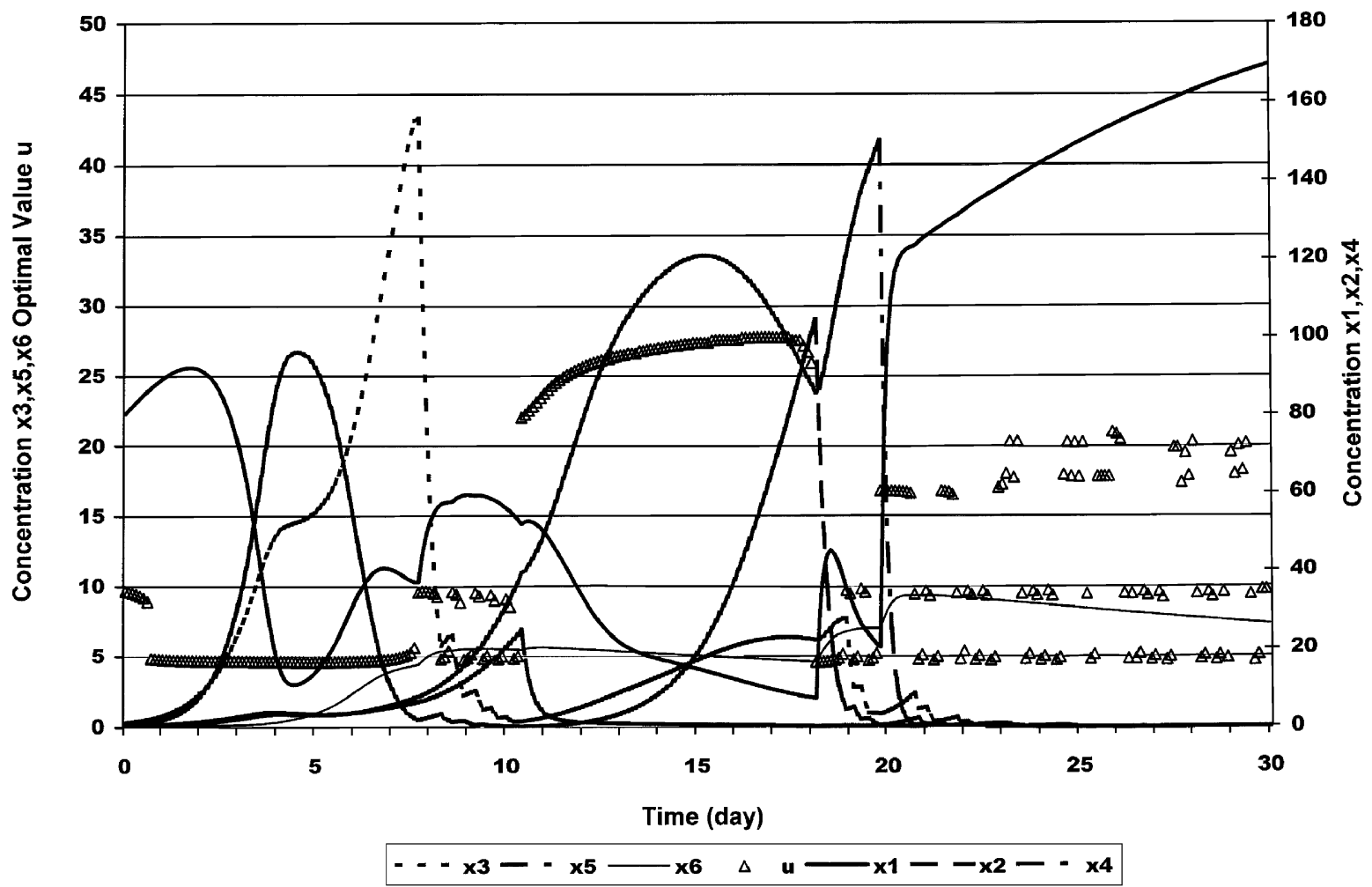

Fig. 10. Optimal solution with global strategy under constant environmental conditions. Initial conditions: $x_{1}^{\circ}=80.3, x_{2}^{\circ}=0.4, x_{3}^{\circ}=0.3$, $x_{4}^{\circ}=0.2, x_{5}^{\circ}=0.1, x_{6}^{\circ}=0.1, t=210$.

sistent with the observed changes. Evidently, Daphnia is not in a position to switch between different values of $u$ rapidly, as predicted by the model. However, it can be assumed that an intermediate value of $u$ is in fact selected, or some other mechanism used for coping with this problem in reality.

Simulations with the model suggest that both the number of species surviving and their abundance depends on zooplankton food selectivity. This means that the optimum strategy of an organism in an ecosystem food web depends both on mutual interactions between the change of food selectivity by zooplankton and changes of the reaction of phytoplankton species on the environment. Because of the prevalence of nonlinear, mostly feedback relations within the ecosystem and between organism sizes and their physiological parameters, it is impossible to intuitively predict the outcome of various situations.
Chemostat model with one growth-limiting nutrient exhibits competetive exclusion or chemostat is an inadequate environment for either population to survive.

The main indication of the model results is that food selectivity based on maximal production of biomass affects the survival of algae of different sizes $\left(x_{2}-x_{5}\right)$ in the model. In the case of short-term strategy population dynamic resulting from a model presented that Daphnia followed the prediction of optimal foraging theory (Křiván, 1996; Křiván and Sikder, 1999; Křiván and Eisner, 2003). When we consider a long-term strategy, the results of this study contradict the instantenous maximal feeding strategy and are in agreement with the finding by Plath (1998).

The higher biomass of zooplankton obtained in the case of integral formulation points towards the assumption that the organisms do better if not reacting only to the immediate changes, but having developed 
mechanisms consistent with more long-term consideration.

\section{Acknowledgements}

We are grateful to Dr. D. Miklisová for her suggestions and thoughtful comments on an earlier draft of this paper.

\section{References}

Bergquist, A.M., Carpenter, S.R., Latino, J.S., 1985. Shifts in phytoplankton size structure and community composition during grazing by contrasting zooplankton assemblages. Limnol. Oceanogr. 30, 1037-1045.

Brendelberger, H., 1985. Filter mesh-size and retention efficienty for small particles: comparative studies with Cladocera. Arch. Hydrobiol. Beih. Ergebn. Limnol. 21, 135-146.

Brendelberger, H., Herbeck, M., Lang, H., Lampert, W., 1986. Daphnia's filters are not solid walls. Arch. Hydrobiol. 107, 197-202.

Brunovský, P., 1980. Mathematical Theory of Optimal Control, Alpha, Bratislava, p. 196 (in Slovak).

Carpenter, S.R., Kitchell, J.F., 1984. Plankton community structure and limnetic primary production. Am. Nat. 124, 159-172.

Fryer, G., 1987. The feeding mechanisms of the Daphnidae (Crustacea: Cladocera): recent suggestions and neglected considerations. J. Plankton Res. 9, 419-432.

Ganf, G.G., Shiel, R.J., 1985. Particle capture by Daphnia carinata. Aust. J. Mar. Freshwater Res. 36, 371-381.

Gerritsen, J., Porter, K., Strickler, R., 1988. Not by sieving alone: observations on suspension feeding in Daphnia. Bull. Mar. Sci. 43, 366-376.

Haney, J.F., 1985. Regulation of Cladoceran filtering rates by body size, food concentration, and diel feeding patterns. Limnol. Oceanogr. 30, 397-411.

Kasprzak, P., Vyhnálek, V., Straškraba, M., 1986. Feeding and food selection in Daphnia pulicaria (Crustacea: Cladocera). Limnologica (Berlin) 17, 309-323.

Kmet, T., 1996. Material recycling in a closed aquatic ecosystem I. Nitrogen transformation cycle and preferential utilization of ammonium to nitrate as an optimal control problem. Bull. Math. Biol. 58, 957-982.

Kmeť, T., Straškraba, M., 1989. Global behavior of a generalized aquatic ecosystem model. Ecol. Modell. 45, 95-110.

Kořínek, V., Krepelová-Machková, B., Machánek, J., 1986. Filtering structures of Cladocera and their ecological significance II. Relation between the concentration of the seston and the size of filtering combs in some species of the genera Daphnia and Ceriodaphnia. Věst. čs. Společ. Zool. 50, 244-258.

Koza, V., Kořínek, V., 1985. Adaptability of the filtration screen in Daphnia: another answer to the selective pressure of the environment. Arch. Hydrobiol. Beih. Ergebn. Limnol. 21, 193198.
Křiván, V., 1996. Optimal foraging and predator-prey dynamics. Theor. Popul. Biol. 49, 265-290.

Křiván, V., Sikder, A., 1999. Optimal foraging and predator-prey dynamics, II. Theor. Popul. Biol. 55, 111-126.

Křiván, V., Eisner, J., 2003. Optimal foraging and predator-prey dynamics, III. Theor. Popul. Biol. 55, 111-126.

Lampert, W., 1987. In: Peters, R.H., De Bernardi, R. (Eds.), Feeding and Nutrition in Daphnia. Daphnia Mem. Ist. Ital. Idrobiol. 45, 143-192.

Lampert, W., Brendelberg, 1996. Strategies of phenotypic low-food adaptation in Daphnia: filter screens, mesh sizes, and appendage beat rates. Limnol. Oceanogr. 41 (2), 216223.

Lehman, J.T., 1976. The filter feeder as an optimal forager and the predicted shapes of feeding curves. Limnol. Oceanogr. 21, 501-516.

Lehman, J.T., Sandgren, C.D., 1985. Species-specific rates of growth and grazing loss among freshwater algae. Limnol. Oceanogr. 30, 34-46.

Li, B., Wolkowicz, G.S.K., Kuang, Y., 2000. Global asymptotic behaviour of a chemostat move with two perfectly complementary resources and distributed delay. SIAM J. Appl. Math. 60, 2058-2086.

Li, B., Smith, H., 2001. How many species can two essential resources support? SIAM J. Appl. Math. 62, 336-366.

Machacek, J., 1998. What can we learn from Daphnia filtering screen? J. Plankton Res. 20, 1645-1650.

Mangalo, P., 1987. Variation in the intersetular distance of filter setae of Simoc ephalus vetulus (O. F. Müller) (Crustacea-Cladocera). Freshwater Biol. 17, 169-176.

Meise, C.J., Munns Jr., W.R., Hairston Jr., N.G., 1985. An analysis of the feeding behavior of Daphnia pulex. Limnol. Oceanogr. 30, 862-870.

Peters, R.H., De Bernardi R. (Eds.), 1987. Daphnia, Mem Ist. Ital. Idrobiol. 45, 1-502.

Pierre, D.A., Lowe, M.J., 1975. Mathematical Programming via Augmented Langrangians. An Introduction with Computer Programs, Addison-Wesley, London, p. 385.

Plath, K., 1998. Adaptive feeeding of daphnia magna inn response to short-term starvation. Limnol. Oceanogr. 43, 593-599.

Pontryagin, L.S., Boltyanski, R.V., Gamkrelidze, E.F., Mischenko, V.G., 1983. The Mathematical Theory of Optimal Processes. Nauka, Moscow, p. 392 (in Russian).

Pop, M., 1991. Mechanisms of the filtering area adaptation in Daphnia. Hydrobiologia 225, 169-176.

Porter, K.G., Orcutt Jr., J.D., Gerritsen, J., 1983a. Functional response and fitness in a generalist filter feeder, Daphnia magna (Cladocera: Crustacea). Ecology 64, 735-742.

Porter, K.G., Gerritsen, J., Orcutt Jr., J.D., 1982. The effect of food concentration on swimming patterns, feeding behavior, ingestion, assimilation, and respiration by Daphnia. Limnol. Oceanogr. 27, 935-949.

Radtke, E., Straškraba, M., 1982. Self-optimization in a phytoplankton model. Ecol. Modell. 9, 247-268.

Scheffer, M.C., 1999. The effect of aquatic vegetation on turbidity; how important are the filter feeders? Hydrobiologia 409, 307316. 
Scheffer, M.C., Rinaldi, S., Kuznetsov, Y.A., 2000. Effects of fish on plankton dynamics: a theoretical analysis. Can. J. Fish. Aquat. Sci. 57, 1208-1219.

Smith, H.L., Waltman, P., 1995. The Theory of the Chemostat. Cambride University Press, Cambrige, UK, p. 254.

Stearns, S.C., 1977. The evolution of life history traits: a critique of the theory and a review of the data. Annu. Rev. Ecol. Syst. $8,145-171$.

Straškraba, M., Gnauck, P., 1985. Freshwater Ecosystems. Modelling and Simulation. Developments in Environmental Modelling. Elsevier, Amsterdam, p. 309.
Yoshizawa, T., 1975. Stability Theory of periodic Solutions and Almost Periodic Solutions. Springer, New York, p. 233.

Zaret, T.M., 1980. Predation and Freshwater Communities. Yale University Press, New Haven, p. 187.

Wolkowicz, G.S.K., Xia, H., 1997. Global asymptotic behaviuor of chemostat model with discrete delays. SIAM J. Appl. Math. 57, 1019-1043.

Wolkowicz, G.S.K., Xia, H., Ruan, S., 1997. Competition in the chemostat: a distributed delay model and its global asymptotic behaviour. SIAM J. Appl. Math. 57, 11811310. 